\title{
Is it time to loosen the restrictions on athletes with cardiac disorders competing in sport?
}

\author{
Rui Providência, ${ }^{1}$ Carina Teixeira, ${ }^{2}$ Oliver Segal, ${ }^{1}$ Augustus Ullstein, ${ }^{3}$ \\ Kim T Mueser, ${ }^{2}$ Pier Lambiase ${ }^{1}$
}

Sudden cardiac death (SCD) in young athletes is a rare and dramatic event. Initial consensus guidelines from 2005 recommend restriction from competitive sports for all athletes with hereditary cardiomyopathies and channelopathies, with very minor exceptions. ${ }^{1}$

\section{THE FIELD HAS CHANGED: NEW DATA SUPPORT A NEW APPROACH}

After decades of a conservative sports cardiology approach, recent findings call these universal restrictions into question. First, data on the use of automatic external defibrillators (AEDs) for witnessed sudden cardiac arrest (SCA) in sports have been reassuring. ${ }^{2}$ When SCA is properly recognised and an AED immediately available, survival from SCA during sport is largely possible.

Second, two reports, one focusing on long QT syndrome in athletes, ${ }^{3}$ and another on catecholaminergic ventricular tachycardia, ${ }^{4}$ have suggested that the risk of competition may be acceptable if athletes are well-informed and fully compliant with therapy. A recent task force of the American Heart Association and American College of Cardiology has suggested that competitive sports practice may be permissible in some athletes with channelopathies, assuming that appropriate precautionary measures are in place. Specifically, avoidance of exacerbating drugs, avoidance of dehydration, appropriate electrolyte replenishment (with drinks containing $\mathrm{Mg}^{2+}$ and $\mathrm{K}^{+}$) and establishment of an emergency action plan with staff trained in cardiopulmonary resuscitation and access to an AED. ${ }^{5}$

Third, in a recently analysis of 184 consecutive deaths in patients with

\footnotetext{
${ }^{1}$ Barts Heart Centre, Cardiac Electrophysiology Department, St. Bartholomew's Hospital, Barts NHS Trust, London, UK

${ }^{2}$ Center for Psychiatric Rehabilitation, Boston University, Boston, Massachusetts, USA

${ }^{3}$ Thirty Nine Essex Street LLP, London, UK
}

Correspondence to Dr Rui Providência, Barts Heart Centre, Cardiac Electrophysiology Department, St. Bartholomew's Hospital, Barts NHS Trust, West Smithfield, London EC1A 7BE, UK: rui_providencia@yahoo.com hypertrophic cardiomyopathy referred to a single cardiac pathology centre, the authors observed that $81 \%$ of deaths occurred at rest, unrelated to exertion. ${ }^{6}$ In most cases of sudden death on exertion, a diagnosis was missed during life. These data suggest that diagnosing these individuals before a final ventricular arrhythmia occurs is of utmost importance, as it may allow the implementation of effective preventive measures, such as implantable cardioverter defibrillators (ICDs).

Fourth, our understanding of athletes with ICDs has progressed from data provided by the ICD Sports Safety Registry. In this multicentre, multinational registry no major adverse events (tachyarrhythmic death, externally resuscitated tachyarrhythmia during or after sports or severe injury resulting from arrhythmia-related syncope or shock during sports) were observed, suggesting that athletes can take part in sports without serious injury or failure of the ICD to terminate the arrhythmia. $^{7}$

After following the trajectory of thousands of disqualified athletes over the years, we now realise that we lacked knowledge about the natural history of these disease entities and that old recommendations ${ }^{1}$ were overcautious, as competitive sports might, after all, not cause a major cardiovascular event in all these individuals.

This understanding should prompt us to shift to a more balanced, but still cautious, approach when dealing with potential disqualification decisions in athletes with identified cardiac disorders.

\section{TIME FOR ATHLETE EMPOWERMENT}

Over the past few decades, medicine in general has become more open to enabling the participation of patients in decisions about the diagnosis and treatment of their conditions, a concept known as 'empowerment', which is being implemented more widely. ${ }^{8}$ A step forward with regard to cardiac disorders includes empowerment and shared decision-making, with placement of the athlete in a central role for planning their future.
Accordingly, we believe that it is the responsibility of the physician to inform athletes about the disease, natural history, treatment options, areas of uncertainty, and to assist them in making their decision based on their own values, and the underlying estimated risk of SCD. Can we deny these athletes the right to expose themselves to a small and uncertain risk that can be substantially reduced in most circumstances by AEDs, ICDs or medication, while we accept the risks of death or traumatic brain injury in motor sports and contact sports such as boxing/kick boxing, American football and rugby?

\section{CARDIAC DISORDERS AND CONTRACTUAL ISSUES}

A special situation occurs for team physicians. Even though physicians employed by teams should still have the same empowering approach and obligations towards the athlete/patient, additional complexity and ethical issues arise when treating athletes finalising a financial contract. The team physician is obliged in his/her role to provide information to the team management about the athlete's health status. Accordingly, management may be concerned about the risk of SCD and the effect on their club, the possibility of disease progression such that the athlete needs to abandon sports, or the potential impact on the transfer fee if trying to negotiate with another club. If this occurs and the club aborts the signing of a contract, assuming the athlete is willing to compete, he/she will have to find a sports club who accepts the potential risks of the cardiac problem. It is ultimately up to the management to decide whether or not they accept hiring of the athlete. However, it should be up to the athlete-not the physicianwhether they want to compete after being informed of the risk.

In conclusion, we believe this emerging evidence indicates that for many cardiac conditions the time has now come for sports cardiologists and team physicians to abandon a paternalistic approach and involve athletes in the decision-making process. After all, it is their lives and goals we are deciding, and to a certain point this can be considered a matter of free will and human rights. This should ideally be formalised in an informed consent process between the physician, athlete and sports team, outlining the known and unknown risks and recording that the athlete is making a fully informed decision to compete.

Contributors RP and CT identified \& proposed the need for the empowerment in this setting and wrote the first draft of the manuscript, which was 
thoroughly revised by PL and OS. A second draft of the manuscript was then prepared and discussed with AW who provided legal advice and suggested areas of improvement and KM who gave advice on empowerment issues. The final version of the manuscript was revised by all authors, and approved before submission.

Funding $\mathrm{CT}$ was funded by the Advanced Rehabilitation Research Training program (Grant \#90AR5018) of the National Institute on Disability Independent Living and Rehabilitation Research (NIDILRR), housed within the Agency for Community Living (ACL) at the Department of Health and Human Services (HHS). The contents of this project do not necessarily represent the policy of NIDILRR, ACL, HHS, and you should not assume endorsement by the US Federal Government. PL was supported by University College of London Hospitals Biomedicine Research Centre, a Partnership between University College of London and University College of London Hospitals NHS Trust, funded by the National Institute for Health Research (NIHR); British Heart Foundation.

Competing interests None declared.

Provenance and peer review Not commissioned; externally peer reviewed.

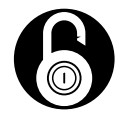

\section{OPEN ACCESS}

Open Access This is an Open Access article distributed in accordance with the terms of the Creative Commons Attribution (CC BY 4.0) license, which permits others to distribute, remix, adapt and build upon this work, for commercial use, provided the original work is properly cited. See: http:// creativecommons.org/licenses/by/4.0/

(C) Article author(s) (or their employer(s) unless otherwise stated in the text of the article) 2017. All rights reserved. No commercial use is permitted unless otherwise expressly granted.

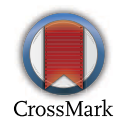

To cite Providência R, Teixeira C, Segal 0 , et al. Br J Sports Med 2017;51:1056-1057.

Revised 20 February 2017

Accepted 27 March 2017

Published Online First 28 April 2017

Br J Sports Med 2017;51:1056-1057. doi:10.1136/bjsports-2016-097002

\section{REFERENCES}

1 Pelliccia A, Fagard R, Bjørnstad HH, et al; Study Group of Sports Cardiology of the Working Group of Cardiac Rehabilitation and Exercise Physiology, Working Group of Myocardial and Pericardial Diseases of the European Society of Cardiology. Recommendations for competitive sports participation in Athletes with cardiovascular disease: a consensus document from the study group of sports cardiology of the working group of cardiac rehabilitation and exercise physiology and the working group of myocardial and pericardial diseases of the european society of cardiology. Eur Heart J 2005;26:1422-45.
2 Drezner JA, Toresdahl BG, Rao AL, et al. Outcomes from sudden cardiac arrest in US high schools: a 2-year prospective study from the national registry for AED use in sports. Br J Sports Med 2013;47:1179-83.

3 Aziz PF, Sweeten T, Vogel RL, et al. Sports participation in genotype positive children with long QT syndrome. JACC Clin Electrophysiol 2015;1:62-70.

4 Ostby SA, Bos JM, Owen HJ, et al. Competitive sports participation in patients with catecholaminergic polymorphic ventricular tachycardia: a single center's early experience. JACC Clin Eelectrophysiol 2016:2:253-62.

5 Ackerman MJ, Zipes DP, Kovacs RJ, et al; American Heart Association Electrocardiography and Arrhythmias Committee of Council on Clinical Cardiology, Council on Cardiovascular Disease in Young, Council on Cardiovascular and Stroke Nursing, Council on Functional Genomics and Translational Biology, and American College of Cardiology. Eligibility and disqualification recommendations for competitive athletes with cardiovascular abnormalities: task force 10: the cardiac channelopathies: a scientific statement from the American Heart Association and American College of Cardiology. Circulation 2015;132:e326-9.

6 Finocchiaro G, Papadakis M, Dhutia H. Circumstances of sudden death in hypertrophic cardiomyopathy. data from a large pathology registry. Eur Heart $J$ 2016;37:1226-7.

7 Lampert R, Olshansky B, Heidbuchel H, et al. Safety of sports for athletes with implantable cardioverterdefibrillators: results of a prospective, multinational registry. Circulation 2013;127:2021-30.

8 Pulvirenti M, McMillan J, Lawn S, Empowerment LS. Empowerment, patient centred care and selfmanagement. Health Expect 2014;17:303-10. 